\title{
Giant Cell Tumour of Mandible: Report of a Rare Case
}

\author{
Arun Dehadaray • Maitri Kaushik • \\ Prasun Mishra $\cdot$ Vikrant Sagar
}

Received: 25 September 2011/ Accepted: 24 November 2011/Published online: 13 December 2011

(C) Association of Otolaryngologists of India 2011

\begin{abstract}
There are various reports of giant cell tumour of long bones but the documented evidence of occurrence of giant cell tumour of mandible is very rare. Because of extreme rarity of occurrence we report one such case. The patient was a 45 year male presented with hard swelling in region of parotid. In CT scan was suggestive of a heterogeneously enhancing lesion lying deep to right parotid gland. It showed central necrosis and erosion of the right coronoid process of mandible. FNAC report was that of giant cell tumour. Tumour was surgically excised preserving the facial nerve and curetting of coronoid process of mandible. He is on follow up till date with no facial palsy and no sign of recurrence.
\end{abstract}

Keywords Giant cell tumor - Mandible - Osteoclastoma . Facial nerve

\section{Introduction}

Giant cell tumours (osteoclastoma) arise from the metaphysis of long bones. They are distinctive neoplasms characterized by a profuse multinucleate giant cells scattered throughout the stroma of mononuclear cells. These giant cells have some similarity with osteoclasts, and so are called osteoclastoma [1]. These tumours are more common in young people in 2nd to 3rd decade of life [2] and have greater predilection for females. These tumour are known mostly in long bones and their occurrence in craniofacial bone more so in mandible is extremely rare [3].

A. Dehadaray · M. Kaushik · P. Mishra $(\bowtie) \cdot$ V. Sagar

Department of Otorhinolaryngology and Head Neck Surgery,

Bharti Vidyapeeth Medical College, Pune, India

e-mail: majorprasun@yahoo.co.in
In this case report we share our experience of managing one such extremely rare case of giant cell osteoclastoma case of mandible. The learning objective of this article is to present the diagnosis and management of this rare lesion along with short discussion on the characteristics inherent to GCT.

\section{Case Report}

A 45 year old male presented to the ENT OPD of our tertiary care teaching hospital, with complaints of swelling of face on right side in the region of parotid for 7 months. The swelling was slowly progressive, associated with pain. He also had difficulty in mouth opening and in chewing food. There was no history of significant weight loss or decreased appetite. Patient had a history of blunt trauma on the right side of face 3 years back. There was no family history of similar swelling.

Examination revealed a $7 \mathrm{~cm} \times 5 \mathrm{~cm}$, non tender, hard, globular, single swelling on right side of face in region of parotid with stretched overlying skin (Fig. 1). He had trismus restricted to one finger mouth opening. There was no facial palsy and rest of ENT examination was normal.

Haematological work up of patient was within limits. Serum calcium and phosphorus were also within normal limits.

The FNAC from the tumour was reported numerous three dimensional large cells with centrally placed vesicular nuclei suggestive of giant cell tumour (osteoclastoma) of ramus of mandible.

A multi slice CT scan was suggestive of a heterogeneously enhancing lesion in the infratemporal fossa lying deep to right parotid gland. It showed central necrosis and erosion of the right coronoid process of mandible. Neck did not show any significant lymph node enlargement (Figs. 2, 3). 


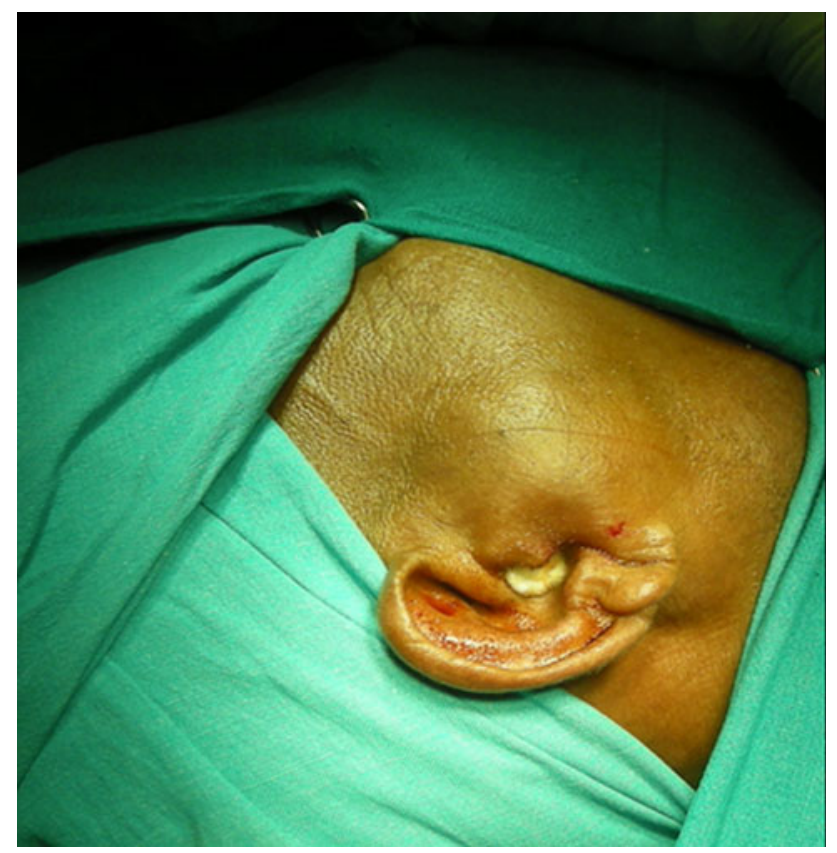

Fig. 1 Tumour in region of parotid

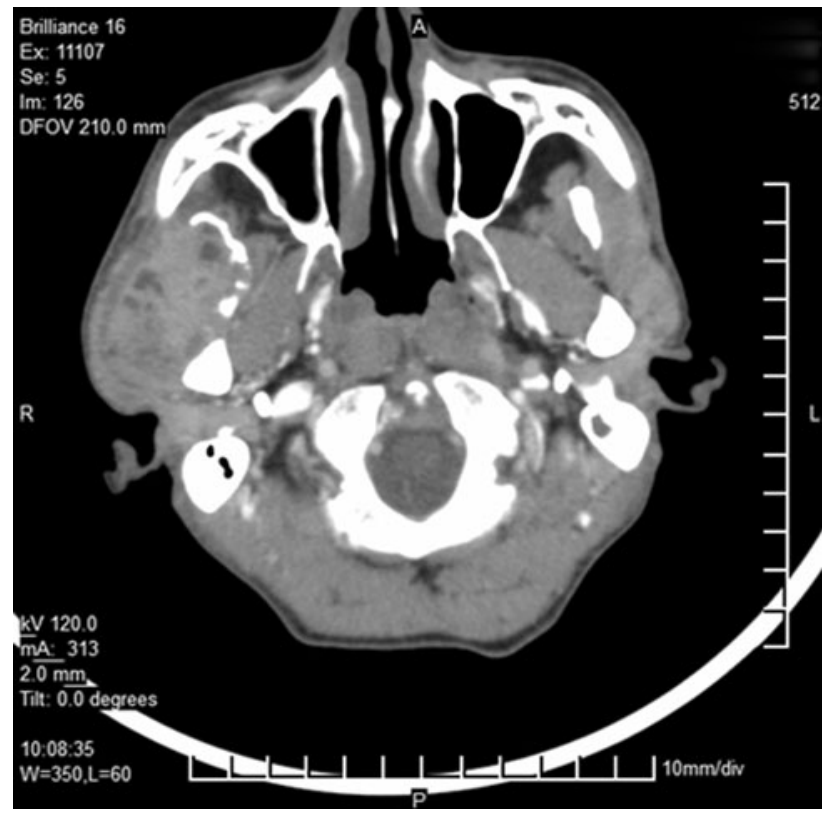

Fig. 2 MSCT scan of Neck

In view of the cytology report and progressive tumour it was decided to surgically excise the tumour. Intra-operatively it was a well encapsulated tumour of the coronoid process of mandible lying deep to parotid gland and deep to facial nerve. As the superficial lobe of parotid gland was reflected the facial nerve was seen stretched and lying over the tumour. Communicating branch of buccal and

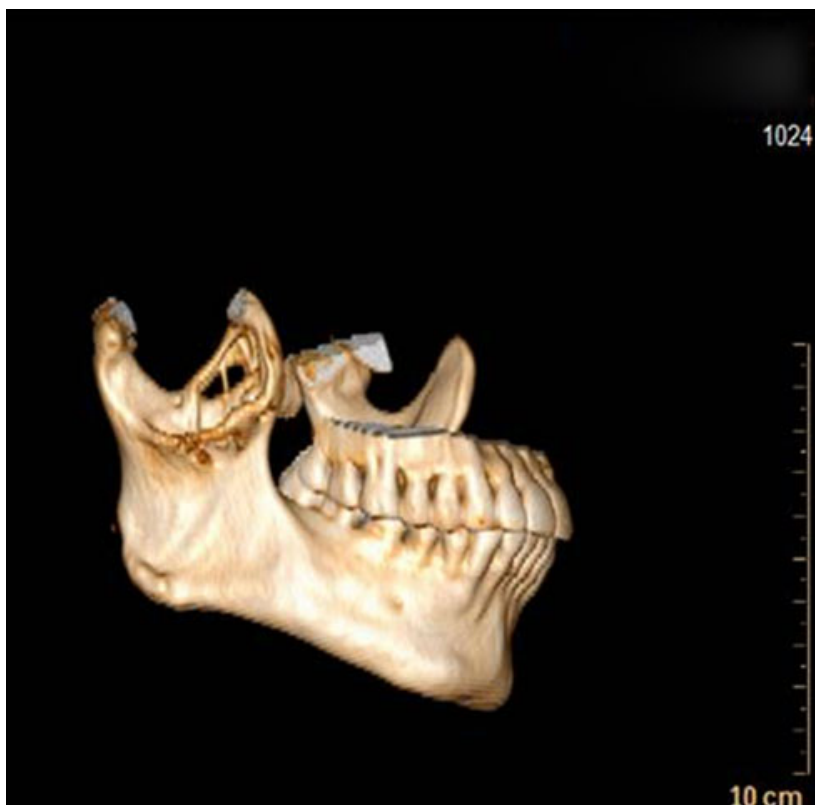

Fig. 3 3D reconstruction of Tumour

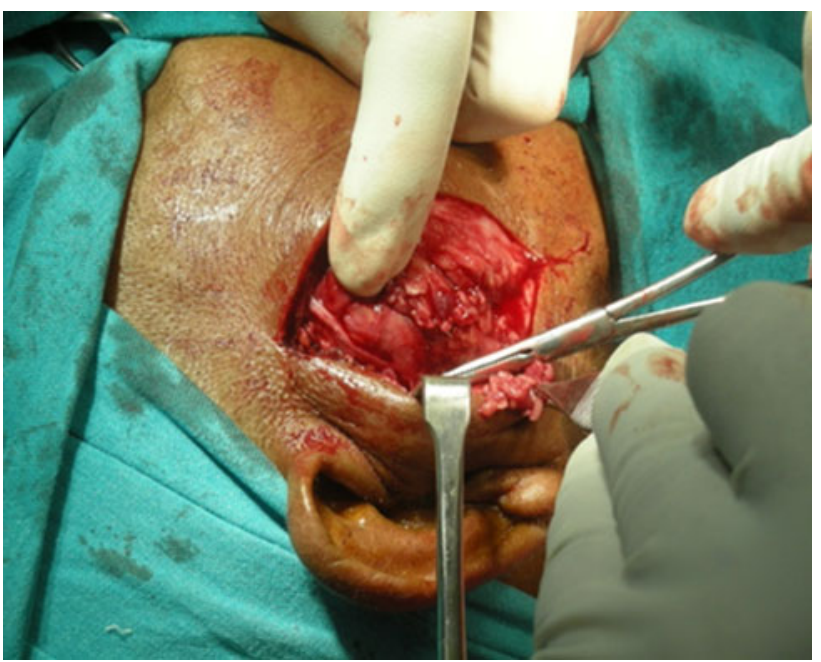

Fig. 4 Intraoperative photograph showing the tumour

zygomatic nerve was cut to gain access to tumour and then the whole tumour excised with curetting the remaining part (Fig. 4). Post operatively patient did have a mild facial paresis which recovered gradually over 4 weeks.

The histopathology report revealed tumour, composed of many osteoclastic giant cells with plump spindle cells. There was no evidence of any malignancy. Thus the diagnosis of giant cell tumour of ramus of mandible was confirmed (Fig. 5). The patient is kept on monthly follow up and till date after 6 months there is no evidence of recurrence. The facial paresis has completely improved. 


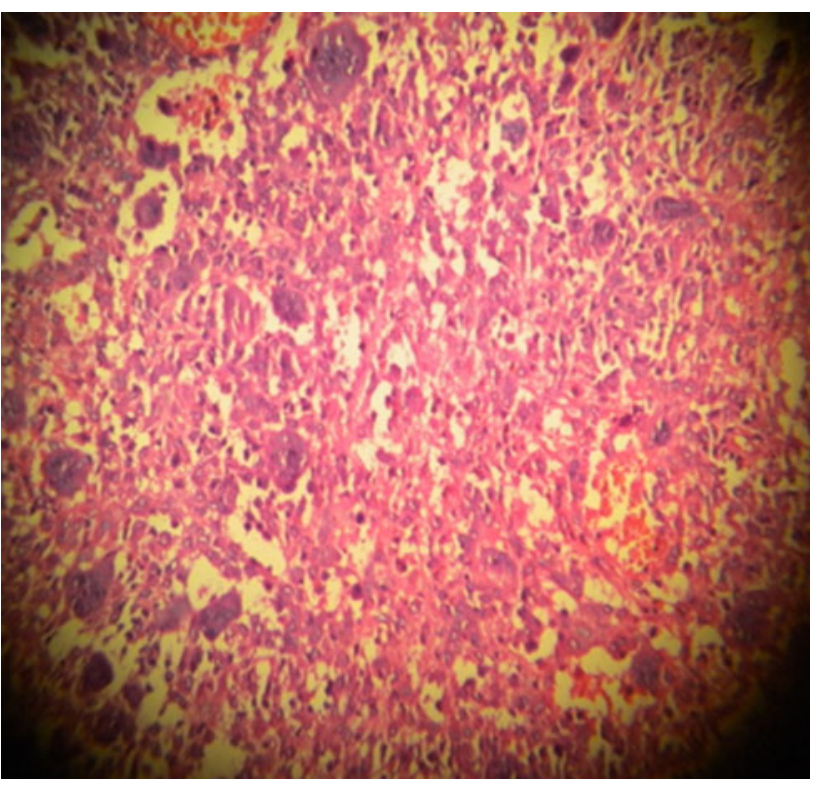

Fig. 5 HPE of Giant cell tumour of ramus of mandible

\section{Discussion}

Osteoclastoma generally arises in the metaphysic of long bones, but when there is fusion of epiphysis the tumour may extend beyond. Rarely do they occur in the bones of the face, skull and spine. No literature evidence is available suggesting the incidence of the occurrence of giant cell tumour in skull bone. In the skull, the tumour follows the distribution of cartilaginous centres of ossification and this supports it's attribution to persisting developmental process occurring in pre-cartilaginous and pre-osseous connective tissues $[4,5]$. When in jaw, they present as slow growing painless tumour. Radiological findings vary from small unilocular lesion to large multilocular lesion with well or ill defined borders. It may also be associated with cortical bone perforation and root resorption [6, 7]. In the present case in point CT scan showed heterogeneously enhancing lesion with central necrosis and erosion of the right coronoid process of mandible. Conservative and surgical modality of management has been considered in management of such giant cell tumour. Conservative treatment is mainly preferred in inactive type of tumour, however, surgical treatment remains the mainstay of treatment in active tumours $[3,8]$. It was Choung et al. [9] who in his report differentiated aggressive and non aggressive lesions on the basis of signs, symptoms and histological features. Aggressive lesions are characterized by one or more of the following features: large size $(>5 \mathrm{~cm})$, pain, paresthesia, root resorption, rapid growth, cortical perforation and a high recurrence rate after surgical curettage. The non aggressive form is characterized by a slow, almost asymptomatic growth that does not perforate the cortical bone or induce root resorption and has low recurrence rate. The case in point was an aggressive type and was managed surgically.

Pathologically giant cell tumours are distinctive neoplasm characterized by a profuse multinucleate giant cells scattered throughout a stroma of mononuclear cells. The neoplastic element is the stromal cells and not the giant cells. The giant cells have some similarity to osteoclasts, and so these neoplasms are called 'osteoclastoma'. Giant cells are characterized by an abundance of acid phosphatase, beta glucuronidase, and succinic dehydrogenase; by absence of alkaline phosphatase. Their cytoplasm shows presence of non-glycogen carbohydrates, principally acid mucopolysaccharides, and complex lipids [1].

Treatment in this condition mainly aims to reduce the symptom and restore normal structure by curettage, resection, amputation, radiation or intra-lesional steroids. Curettage does have a danger of local recurrence, however, resection is justified only when the site of the lesion permits complete removal without impairment of function. Radiation has reported encouraging results but with some reports of leading to malignant transformation of the osteoclastoma [4]. Intralesional steroids have been tried in various studies with good results in non aggressive cases. In the present case surgical resection with curettage was done and patient has been kept on regular follow up till date with no recurrence.

\section{Conclusion}

Giant cell tumour of mandible is a very rare occurrence and here we have aimed to describe one such case managed at our tertiary care centre. Considering the location of tumour in parotid region and extreme rarity of giant cell tumour in mandible, first impression of this tumour was that of parotid mass though it was a giant cell tumour. It is to stress on the fact that for any tumour in region of parotid a CT scan is essential before surgery as there may be some surprises for the surgeon. In aggressive disease surgical modality should be treatment of choice.

\section{References}

1. Schajowicz F (1961) Giant-cell tumors of bone (osteoclastoma). A pathological and histochemical study. J Bone Jt Surg 43:1-29

2. Murphey MD, Nomikos GC, Flemming DJ, Gannon FH, Temple HT, Kransdorf MJ (2001) Imaging of giant cell tumour, giant cell reparative granuloma of bone: radiologic-pathologic correlation. Radiographics 21(5):1283-1309

3. Dario LJ, Carlotti AE Jr, Elson MT, Sauk JJ (1996) Giant cell tumour in the mandible: surgical treatment and implant-supported reconstruction-a clinical report. Pract periodontics. Aesthet Dent 8(6):547-553 quiz 554 
4. Ellis F (1949) Treatment of osteoclastoma by radiation. J Bone Jt Surg 31B(2):268-280

5. Geschickter CF, Copeland MM (1931) Tumors of bone. Am J Cancer

6. De Lange J, Van den Akker HP, Van den Berg H (2007) Central giant cell granuloma of the jaw: a review of the literature with emphasis on therapy options. Oral Surg Oral Med Oral Pathol Oral Radiol Endod 104:603-615

7. Cohen MA, Hertzanu Y (1988) Radiologic features, including those seen with computed tomography, of central giant cell granuloma of the jaws. Oral Surg Oral Med Oral Pathol 65:255-261
8. Mohanty S, Jhamb A (2009) Central giant cell lesion of mandible managed by intralesional triamcinolone injections. A report of two cases and literature review. Med Oral Patol Oral Cir Bucal 14(2):E98-102

9. Chuong R, Kaban LB, Kozakewich H, Perez-Atayde A (1986) Central giant cell lesions of the jaws: a clinicopathologic study. J Oral Maxillofac Surg 44:708-713 